\title{
Estimation of Stress Induces By Malaria Parasite Infection and Effect of Anti-malaria Drugs on Stress Index, Lipid Profile in Uncomplicated Acute Malaria Infected Adult Individuals
}

\author{
ESAN AYODELE ${ }^{1, *}$, TITILAYO OYEDELE. $\mathrm{E}^{2}$ \\ ${ }^{1}$ Haematology Department, Federal Medical Centre, Ido-Ekiti, Ekiti State Nigeria \\ ${ }^{2}$ ACHIEVERS UNIVERSITY, OWO, ONDO STATE, NIGERIA \\ *Corresponding author: ayodelejacob4u@gmail.com
}

Received April 11, 2014; Revised May 21, 2014; Accepted October 07, 2014

\begin{abstract}
Malaria infection is accompanied by increased production of reactive oxygen species which indicates the environment for oxidative stress. Oxidative stress in malaria may originate from several sources including intracellular parasitized erythrocytes and extra-erythrocytes as a result of haemolysis and host response. The aim of this study is to estimate level of stress induces by malaria parasite infection and effect of anti malaria drugs on stress index in uncomplicated acute malaria infected adult individuals. 202 confirmed malaria infected patients were recruited for the study between the ages of 15 - 64 years of both sexes at the general outpatient clinic of the Federal Medical Centre, Ido-Ekiti, Nigeria. 129(63.9\%) were males and 73(36.1\%) were females. Mean \pm SD of cortisol, $M D A$, glucose and HDL in pre anti-malaria drug treatment of age group A were higher compared to other age groups; there is significant difference $(p<0.05)$ observed in cortisol and glucose. Plasmodium falciparum malaria infection is accompanied by increased production of reactive oxygen species which indicates the environment for oxidative stress. The level of stress induced by malaria parasite is corresponded to the severity of infection and age differences; this could be due to the number of exposure to mosquito bites which increases with age and also increase the level of immunity against malaria infection.
\end{abstract}

Keywords: anti-malaria drug, malaria parasite, stress

Cite This Article: esan AyOdele, and TITILAyo OYedele. E, "Estimation of Stress Induces By Malaria Parasite Infection and Effect of Anti-malaria Drugs on Stress Index, Lipid Profile in Uncomplicated Acute Malaria Infected Adult Individuals.” American Journal of Clinical Medicine Research, vol. 2, no. 5 (2014): 87-98. doi: 10.12691/ajcmr-2-5-1.

\section{Introduction}

Stress is a normal physical response to events that makes body feel threatened. Stress response is the way of protecting the body by nervous system responds releasing a flood of stress hormones; including adrenaline and cortisol. Malaria is a serious public health problem in most countries of the tropics. It is a major cause of mortality and morbidity, between 300 and 500 million people suffer acute cases of malaria in 100 developing countries each year, and the majority of the victims are children [1]. In Nigeria about 96 million people are exposed to malaria, and out of these 64 million people get infected and almost 300,000 deaths are being reported annually in the general population [2]. However, the available data indicates that malaria is the most common cause of outpatient visits. It ranks among the five most common causes of death for all ages [3]. Malaria also causes substantial social costs due to the school absenteeism and reduced economic productivity; hence a worker suffering a bout of malaria will lose ten working days on the average. The disease costs countries in Africa more than one percent of their gross domestic product and about ten percent of their expenditure on health [1]. Malaria is caused by protozoan parasites belonging to the genus plasmodium which infects and destroys red blood cells. Four species of plasmodia (Plasmodium falciparum, Plasmodium malariae, Plasmodium ovale and Plasmodium vivax) cause malaria in humans of which Plasmodium falciparum is the most dangerous form of malaria and life threatening in an unprotected, nonimmune population causing high morbidity and mortality. The existence of oxidative stress during acute malaria infection has been demonstrated previously, including depletion of antioxidants [4], increased plasma lipid peroxidation and altered fluidity of erythrocyte membrane [5]. The oxidative stress results from host immune reaction, as an acute phase response, and the intraerythrocytic parasite's metabolic processes. Although the oxidative stress appears to be a common phenomenon in acute infection, it may cause a specific consequence in 
malaria pathogenesis. Oxidative stress is related to the severity of malaria, oxidative stress in malaria may originate from several sources including intracellular parasitized erythrocytes [6] and extra-erythrocytes as a result of haemolysis and host response [4]. Malondialdehyde is an organic compound being generated from reactive oxygen species (ROS) and as such is assayed in vivo as a bio-marker of oxidative stress. Malaria infection has been found to be associated with lipid peroxidation (Malondialdehyde) (MDA) accompanying reduction in antioxidant capacity of the infected patients especially Plasmodium falciparum infection. Various studies have established that malaria infection is accompanied by increased production of reactive oxygen species which indicates the environment for oxidative stress [7]. Malaria parasite is sensitive to oxidative stress and the level of oxidative stress is influenced by the severity of malaria infection [8,9]. Though, oxidative stress destroys malaria parasites but may also render host tissues such as erythrocytes more vulnerable to oxidative damage and thereby resulting to anaemia in malaria infected individuals [10]. Previous study has confirmed that MDA levels may reflect the severity of a disease process [4]. In Malaria infection caused by Plasmodium falciparum and Plasmodium vivax the oxidative stress is due to the over load in reactive oxygen species which create an increase in the oxygen free radicals and failure of normal defence mechanism that increases the antioxidant blood serum levels [11]. Many authors have cited a large number of drugs that cause alterations on the shape and physiology of the red blood cells [12]. Reports have shown that oxidative damage of erythrocyte membrane is the primary cause of reduced capacity of the red blood cells to withstand stress. Destabilization of the red blood cells by anti-malaria drugs could be because of the metabolic consequence of the administered drugs; rapid production and accumulation of ROS overwhelmed antioxidant defence capacities to maintain and sustain membrane integrity of the human erythrocytes and depletion of erythrocyte glutathione concentration. Therefore, the diminishing plasma concentrations with time of the antimalaria metabolites and positive activation of associated redox enzymes [13] might have contributed to diminishing levels of destabilization of human erythrocytes. The most recent advance in anti-malaria chemotherapy has been the use of artemisinin derivatives which may well revolutionize the management of severe disease. The majority of cases of malaria worldwide are mild and can be treated with oral drugs, a minority, mainly because of delays in diagnosis or treatment, may develop complicated, life-threatening disease requiring parenteral therapy. The anti-malaria drugs were able to achieve the observed varying degree of liver catalyzes reduction probably through a feedback inhibition or oxidative inactivation of enzyme protein due to an excess reactive oxygen species generation [14]. Thus, excess hydrogen peroxide production from generation of free radicals by artemisinin derivatives due to cleavage of the endoperoxide bridge to cause subsequent destruction of the malaria parasite [15]. Microscopic examination of stained blood films is the gold standard for routine malaria diagnosis. Parasite density has to be reliably evaluated in order to deal with discriminatory thresholds of parasitemia. Besides, parasite counts are important especially in Plasmodium falciparum infections, which are always considered as potentially dangerous because Plasmodium falciparum infects erythrocytes of any age with the potential of development of high-grade parasitaemia, due to the rapid multiplication of this parasite, the parasite count can increase upto 20fold over a period of 48 hours without treatment. In the clinical setting, the level of parasitaemia is useful as one of the criteria in defining "severe $P$. falciparum malaria" and to monitor the effect of anti-malarial therapy [16]. A clinical malaria was defined as Plasmodium falciparum parasitaemia $>2,500$ parasites/ $\mu$ l and axillary temperature $\geq 37.5^{\circ} \mathrm{C}$ or reported fever over the previous 24 hours. The aim of this study therefore, is to estimate level of stress induces by malaria parasite infection and effect of antimalaria drugs on stress index in uncomplicated acute malaria infected adult individuals.

\section{Materials and Methods}

\subsection{Study Location}

The study site was Ido town, the headquarters of ido-osi local government in Ekiti State, Nigeria. The secretariat sited in between Ido town and Usi town. It is very close to other local government districts, (Moba, Ijero, Ilejemeje and Ado). The local government comprises rural towns: Aaye, Ido, Usi, Ayetoro, Ilogbo, Osi, Ifaki, Orin, Ora, Igbole and some other smaller villages, inhabited mainly by the Ekitis, but with some non-Ekitis fund living peacefully among the people. People in Ido - Osi cherish farming, education, trading and practicing majorly Christianity religion. According to 1991 Census, the Local government has a total population of 107,000 people with eleven electoral wards in the Local government. The climate is characterized by two main seasons; the rainy and the dry season, the rainy season starts in March to October while the dry season is between November to February. The total rainfall in the area is $450 \mathrm{~mm}$ giving a mean monthly rainfall of $121 \mathrm{~mm}$. There is a sharp fall in rainfall at a period between July and August. Temperature in the region is high throughout the year with a means monthly temperature of $27 \mathrm{C}$ and a range of 3.7c between the month of highest temperature (February) and the month of lowest (August).

\subsection{Subjects Selection}

Two hundred and two confirmed malaria infected patients were recruited for the study between the ages of $15-64$ years of both sexes at the general outpatient clinic of the Federal Medical Centre, Ido-Ekiti, Ekiti State, Nigeria. One hundred and two apparently healthy malaria negative subjects were drowning from hospital staff at Federal Medical Centre, Ido-Ekiti which serves as study control group and comprising both sexes between the ages $15-64$ years. The study was conducted with an informed consent of the patients. Ethical approval was obtained from ethical committee of Federal Medical Centre, IdoEkiti, Ekiti State.

\subsection{Sample Collection}

About $7 \mathrm{ml}$ of blood sample was collected from each subject on the first day of visiting hospital as baseline 
sample grouped as pre anti-malaria drug treatment sample, after the patient has been clinically diagnosis for malaria infection and confirmed using malaria rapid kit, another $7 \mathrm{ml}$ of blood sample was collected on the second or third day from the same patient after taking anti-malaria drugs then grouped as post anti-malaria drug treatment sample. Out of $7 \mathrm{ml}$ blood sample collected; $3 \mathrm{ml}$ of blood sample was dispensed into plain bottles; serum was extracted to assay stress index hormone (cortisol) using ELISA method by monobind Inc. lake forest and malondialdehyde (MDA) using Thiobarbituric Acid Assay method, $1 \mathrm{ml}$ of blood sample was dispensed into fluoride oxalate bottles to assay blood glucose level using glucose oxidase test method and $3 \mathrm{ml}$ of blood sample was dispensed into lithum heparin bottle to assay lipid profile using randox kit. Malaria parasite was screened for using commercially prepared malaria rapid test kit; also thick and thin blood film was made for microscopic gold standard diagnosis of malaria parasite infection; malaria parasite detection, malaria parasite count and malaria parasite species identification were also determined. Questionnaire was used to obtain the demographic characteristics and other relevant information for the study.

\section{Methodology}

\section{Diagnosis of Malaria Parasite Using a Rapid Diagnostic Kit Test}

Malaria plasmodium falciparum was screened for using commercially prepared malaria rapid test kit. The test device is a rapid chromatographic immunoassay for the qualitative detection of circulation of plasmodium falciparum in whole blood.

\section{Principle}

The malaria plasmodium falciparum rapid test device (whole blood) is a qualitative, membrane based immunoassay for the detection of plasmodium falciparum antigen in whole blood. The membrane is pre-coated with anti-HRP-II antibody. During testing, the whole blood specimen reacts with the dye conjugate, which has been pre-coated in the test strip. The mixture then migrates upward on the membrane chromatographically by capillary action and reacts with anti-HRP-II antibody on the membrane on the test line. If the specimen contains HRP-II, a coloured line will appear in the test region. The absence of the coloured line in the test region indicates that the specimen does not contain HRP-II. To serve as a procedure control, a coloured line will always appear in the control region indicating that proper volume of specimen has been added and membrane wicking has coloured.

\section{Procedure}

The procedure was as described by the manufacturer of the kit (Acon Laboratories, Inc.). 20ul of whole blood was pipette into clean labeled test tube, 120ul of buffer solution was added and waited for 1minutes, contents in the test tube was mixed, 140ul of mixed blood sample and buffer solution was pipette into specimen well on test device and wait for colour line(s) to appear. The result was read at 15 minutes. Interpretation of results: for positive result, two distinct coloured lines were appeared: one line was in control region and another line was in test region. For negative result: only one coloured line was appeared in the control region, result was invalid if control line fails to appear

\subsection{Microscopic Diagnosis of Malaria Parasite Using Thick and Thin Stained Blood Film}

\subsubsection{Thick and Thin Stained Blood Film}

Thick blood film was made and stained using Giemsa's staining technique for malaria parasite detection and malaria parasite count. However, thin blood film was also made and stained with Leishman staining technique for plasmodium species identification. Changes in parasitized red cells help to identity plasmodium species and to detect mixed infection of malaria parasite. The number of asexual $P$. falciparium and other species per 200 leukocytes were counted and if ten or more parasites were identified, then the number was recorded, a blood sample was regarded as negative if the examination of thick films failed to show the presence of asexual parasites. The parasite count in relation to the leukocyte count was converted to parasite per micro litre of blood using this mathematical formula;

$$
\begin{aligned}
& \frac{\text { Number of parasites }}{\text { Number of leukocytes }} \times \text { Total WBC count } \\
& =\text { Parasite per micro litre of blood. }
\end{aligned}
$$

\subsubsection{Principle of the Staining}

Staining usually take place at a neutral $\mathrm{pH}$. $\mathrm{pH}$ of blood is 7.4, when buffered at $\mathrm{pH} 6.8$, it brings the $\mathrm{pH}$ to neutral $\mathrm{pH}$ i.e. $\mathrm{pH}$ 7.0. Unlike charges of stain and blood will attract, the basic part of stain methylene blue stained the acidic part of the cell i.e. the nucleus while the acidic part of stain eosin stained the basic part of the stain i.e. cytoplasm.

\subsubsection{Procedure for Staining Thick Blood Film}

The procedure was described by Monica Cheesbrough, 2005 [17]. 3\% of stock Giemsa stain was diluted in buffered water immediately before use. Thick blood film was made on clean grease free glass slide, allowed to airdry and stained with prepared Giemsa stain for 30mintues. Stained slide was rinsed in clean water and allow airdrying before examined under microscope using X100 objective lens. Chromatin of malaria parasite stained dark red and cytoplasm stained blue with Giemsa's stain. The diagnosis of malaria was made with certainty on identification of malaria parasite together with other symptoms associated with malaria infection. The signs and symptoms of malaria infection in humans are caused by the asexual blood stage of the parasite which includes: fever, headache, joint pains, abdominal upset, nausea, vomiting, diarrhoea, and digestive disorders. The presence of malaria parasite, identification of the species of human parasites and relative malaria parasite count in each blood sample was determined from Giemsa stained thick films and Leishman stained thin blood film. Malaria Parasitaemia was confirmed by microscopic examination using X100 objective lens (oil immersion lens). Malaria Parasitaemia was graded as $+=1-10$ parasites per 100 
thick film field, $++=11-100$ parasites per 100 thick film field, $+++=1-10$ parasites per single thick film field, $++++=$ more than 10 parasites per single thick film field after staining for $30 \mathrm{~min}$. Identification of the species of human parasites in the blood films was carried out according to WHO method. A slide was scored as negative when 100 high power fields had been examined for about 30 minutes without seeing any parasites. The amount of relative parasite count in positive smears was done using a simple code from one to four crosses (+ $++++)$ [18].

\subsubsection{Procedure for Staining Thin Blood Film}

Thin blood film was made on clean grease free glass slide and stained using Leishman staining technique; the procedure was described by Monica Cheesbrough, 2005 [17]; the film was allowed to air dry and flooded with Leishman stain for 3minutes. The slide was diluted with buffered distilled water and allowed to stain for 10minutes. Slide was rinsed with water; back of the slide was cleaned with damped cotton wool in methylated spirit. The slide was allowed to air dry and examined under microscope using X100 objective lens.

\subsubsection{Malaria Parasite Count}

The determination of the number of circulating parasites is exceedingly important for clinical purposes to monitor the evolution of the disease and the efficacy of therapy. Quantitative parasitaemia count (Parasite density) was determined by counting the number of asexual parasites (trophozoites, schizonts) present in as many microscopic fields (100x) necessary to count 200 leukocytes in each thick blood film and multiplies by the total white blood cells count of each blood sample. Parasitaemia was graded as low (parasite $<1000 \mu \mathrm{L}^{-1}$ ), moderate $\left(>1000-9,999 \mu \mathrm{L}^{-1}\right)$ and high $\left(>10,000 \mu \mathrm{L}^{-1}\right)$. [19].

$$
\begin{aligned}
& \text { parasites / ul of blood } \\
& =\frac{\text { Number of observed asexual parasites }}{200(\text { Number of leucocytes counted) }} \\
& \quad \times \text { total WBC count / ul }
\end{aligned}
$$

\subsection{Estimation of Cortisol Using Enzyme Linked Immunosorbent Assay (Elisa) Method}

\subsubsection{Principle}

The essential reagents required for an enzyme immunoassay include antibody, enzyme-antigen conjugate and native antigen. Upon mixing biotinylated antibody, enzyme-antigen conjugate and a serum containing the native antigen, a competition reaction result between the native antigen and the enzyme-antigen conjugate for a limited number of antibody binding sites. The enzyme activity in the antibody-bound fraction is inversely proportional to the native antigen concentration.

\subsubsection{Procedure}

Cortisol was estimated using enzyme linked immunosorbent assay (ELISA) method. The procedure was as described by the manufacturer of the kit (Monobind Inc. Lake Forest, CA 92630, USA). 25ul of the serum sample was added into all wells, 50ul of the working cortisol enzyme reagent was also added to all wells; microplate was swirl gently for 20-30seconds, 50ul of cortisol biotin reagent was added to all wells, microplate was swirl gently for 20-30seconds. Microplate was covered and incubated for 60minutes at room temperature; contents of the microplate were discarded by decantation. Microplate was washed with 350ul of wash buffer three times, 100ul of working substrate solution was added to all wells and incubated at room temperature for 15minutes; 50ul of stop solution was added to each well and gently mixed for 15-20seconds. Absorbance in each well was read at 450nm within 30minutes of adding stop solution. The same procedure was performed for standard.

\subsection{Estimation of Malondialdehyde (MDA) Using Thiobarbituric Acid Method by Tomotsu}

Malondialdehyde (MDA) is a three-carbon low molecular weight aldehyde and spontaneous breakdown product of peroxides that can be produced from free radical attack on poly unsaturated fatty acids. The analysis of MDA by the thiobarbituric acid (TBA) assay has been widely employed over many years in biological systems for the assessment of lipid peroxidation. It is a spectrophotometric assay, based upon heating of the sample under acidic conditions to form the adduct of MDA-TBA [20].

\subsubsection{Principle}

Analysis of malondialdehyde (MDA) by the thiobarbituric acid (TBA) is a spectrophotometric assay, based upon heating of the sample under acidic conditions to form the adduct of MDA-TBA.

\subsubsection{Procedure}

Malondialdehyde (MDA) level of the plasma was measured by the following procedure according to Tomotsu. 0.5 plasma was shaken with $2.5 \mathrm{ml}$ of $20 \%$ trichloroacetic acid (TCA) in a $10 \mathrm{ml}$ centrifuge tube. $1 \mathrm{ml}$ of $0.6 \%$ 2-thiobarbituric acid (TBA) was added to the mixture, shaken, and warmed for $30 \mathrm{~min}$ in a boiling water bath followed by rapid cooling. Then it was shaken into a $4 \mathrm{ml}$ of nbutyl- alcohol layer in a separation tube and MDA content in the plasma was determined from the absorbance at 535 and $520 \mathrm{~nm}$ by spectrophotometer against butanol. The standards of $5,10,20 \mathrm{nmol} / \mathrm{ml}$ of 1,1,3,3-tetraethoxypropane (TEP) were used. The results were expressed as nmol/ml plasma [21].

\subsubsection{Preparation of the Standard Curve}

Malondialdehyde (MDA) standard was prepared by dissolving $25 \mu \mathrm{L} \quad 1,1,3,3$ tetraethoxypropane (TEP) in $100 \mathrm{ml}$ of water to give a $1 \mathrm{mM}$ stock solution. Working standard was prepared by hydrolysis $1 \mathrm{ml}$ of TEP stock solution in $50 \mathrm{ml} 1 \%$ sulfuric acid and incubated for 2hours at room temperature. The resulting MDA standard of $20 \mathrm{nmol} / \mathrm{ml}$ was further diluted with $1 \%$ sulfuric acid to yield the final concentration of 10.5, 2.5, 1.25 and 0.625 $\mathrm{nmol} / \mathrm{ml}$ to get the standard curve for the estimation of total MDA [22]. 


\subsection{Estimation of Blood Glucose by Randox}

Blood glucose was estimated using glucose oxidase method.

\subsubsection{Principle}

Glucose is determined after enzymatic oxidation in the presence of glucose oxidase. The hydrogen peroxide formed reacts, under catalysis of peroxidase, with phenol and 4-aminopheazone to form a red - violet quinoneimine dye as indicator.

\subsubsection{Procedure}

The procedure was as described by the manufacturer of the kit (Randox); $0.01 \mathrm{ml}$ of blood sample was pipette into a labeled clean test tube, $0.01 \mathrm{ml}$ of reagent standard was pipette into another labeled clean test tube, $1.00 \mathrm{ml}$ of glucose reagent was pipette into each of the test tube, water blank was used; contents in the test tube was mixed and incubated for 25 minutes at $15^{\circ} \mathrm{C}-25^{\circ} \mathrm{C}$ or 10 minutes at $37^{\circ} \mathrm{C}$. Absorbance was read at $500 \mathrm{~nm}$.

\subsection{Estimation of Lipid Profile}

Lipid profile majorly consist of high density lipoproteins (HDL), low density lipoproteins (LDL), triglycerides and cholesterol.

\subsubsection{Estimation of High Density Lipoproteins by Randox}

High density lipoproteins (HDL) are one of the major classes of plasma lipoproteins which would be estimated using CHOD-PAP method.

\subsubsection{Principle}

Low density lipoproteins (LDL) and chylomicron fractions are precipitated quantitatively by the addition of phosphotungstic acid in the presence of magnesium ions. After centrifugation, the cholesterol concentration in the high density lipoprotein fraction which remains in the supernatant is determined.

\subsubsection{Procedure}

The procedure was as described by the manufacturer of the kit (randox); 200ul of test sample, 200ul of reagent standard and 200ul of control sample was pipette into three different clean test tubes labeled as test, standard and control. 500ulof diluted precipitant was pipette into each test tube, mixed and incubated at room temperature for 10 minutes, for precipitation and then centrifuge for 10 minutes at 4,000 revolution per minutes or 2 minutes at 12,000 revolution per minutes. Clear supernatant from each test tube was separated into three different clean test tubes labeled as test, standard and control. Into another clean test tube labeled as blank, standard, control and test, 100ul of distilled water was pipette into blank test tube, 100ul of reagent standard was pipette into standard test tube, 100ul of control sample was pipette into labeled control test tube and 100ul of test sample was pipette into labeled sample test tube. To all the test tubes, 1000ul of CHOL reagent was added and incubated at room temperature $\left(20-25^{\circ} \mathrm{C}\right)$ for 10 minutes or at $37^{\circ} \mathrm{C}$ for 5 minutes. Absorbance was read at 540nm.

\subsubsection{Estimation of Low Density Lipoproteins}

Low density lipoprotein was determined by Freidewald's formular;

Low density lipoproteins

$=$ Total Cholesterol - Triglycerides 2.2

- High density lipoproteins ( $\mathrm{mmol} / \mathrm{L}$ )

Or

Low density lipoproteins

$=$ Total Cholesterol - Triglycerides 5

-High density lipoproteins in ( $\mathrm{mg} / \mathrm{dL}$ ).

\subsubsection{Estimation of Triglycerides (Trigs) By Randox}

Triglyceride measurements are used in the diagnosis and treatments of disease involving lipid metabolism and various endocrine disorders for example diabetes mellitus, nephrosis and liver obstruction.

\subsubsection{Principle}

Using colorimetric method, triglycerides are determined after enzymatic hydrolysis with lipase. The indicator is a quinoneimine formed from hydrogen-peroxide, 4aminophenazone and 4-chlorophenol under the catalytic influence of peroxidase

\subsubsection{Procedure}

5ul of standard, control and sample was pipette into three different test tubes, 500ul of reagent was added into each test tube, the contents were mixed and incubated at $20^{\circ} \mathrm{C}-25^{\circ} \mathrm{C}$ for 10 minutes or $37^{\circ} \mathrm{C}$ for 5 minutes. The absorbance was read at 500nm using reagent blank.

\subsubsection{Estimation Of Total Cholesterol (Chol)}

Total Cholesterol measurements are used in the diagnosis and treatments of lipid lipoprotein metabolism disorders.

\subsubsection{Principle}

Cholesterol is determined after enzymatic hydrolysis and oxidation. The indicator quinoneimine is formed from hydrogen peroxide and 4-aminoantipyrine in the presence of phenol and peroxidase.

\subsection{Procedure}

5ul of standard, control and sample was pipette into three different test tubes, 500ul of reagent was added into each test tube, the contents were mixed and incubated at $20^{\circ} \mathrm{C}-25^{\circ} \mathrm{C}$ for 10 minutes or $37^{\circ} \mathrm{C}$ for 5 minutes. The absorbance was read at 500nm using reagent blank.

\section{Statistical Analysis}

Data obtained were analyzed using student t-test to compare means. Analysis was performed using computer database software from the statistical package for social sciences (version 16.0 SPSS). A P-value of $<0.05$ was considered statistically significant in all clinical comparisons at $95 \%$ confidence interval. 


\section{Results}

Most of the participants were from rural residence and all of them were infected with Plasmodium falciparum species; patients without malaria parasite in their blood were disqualified from the study. Out of the 202 malaria infected patients 129 (63.9\%) were males and 73 (36.1\%) were females; in control subjects 58 (56.9\%) were males and 44 (43.1\%) were females as shown in the Figure 1.

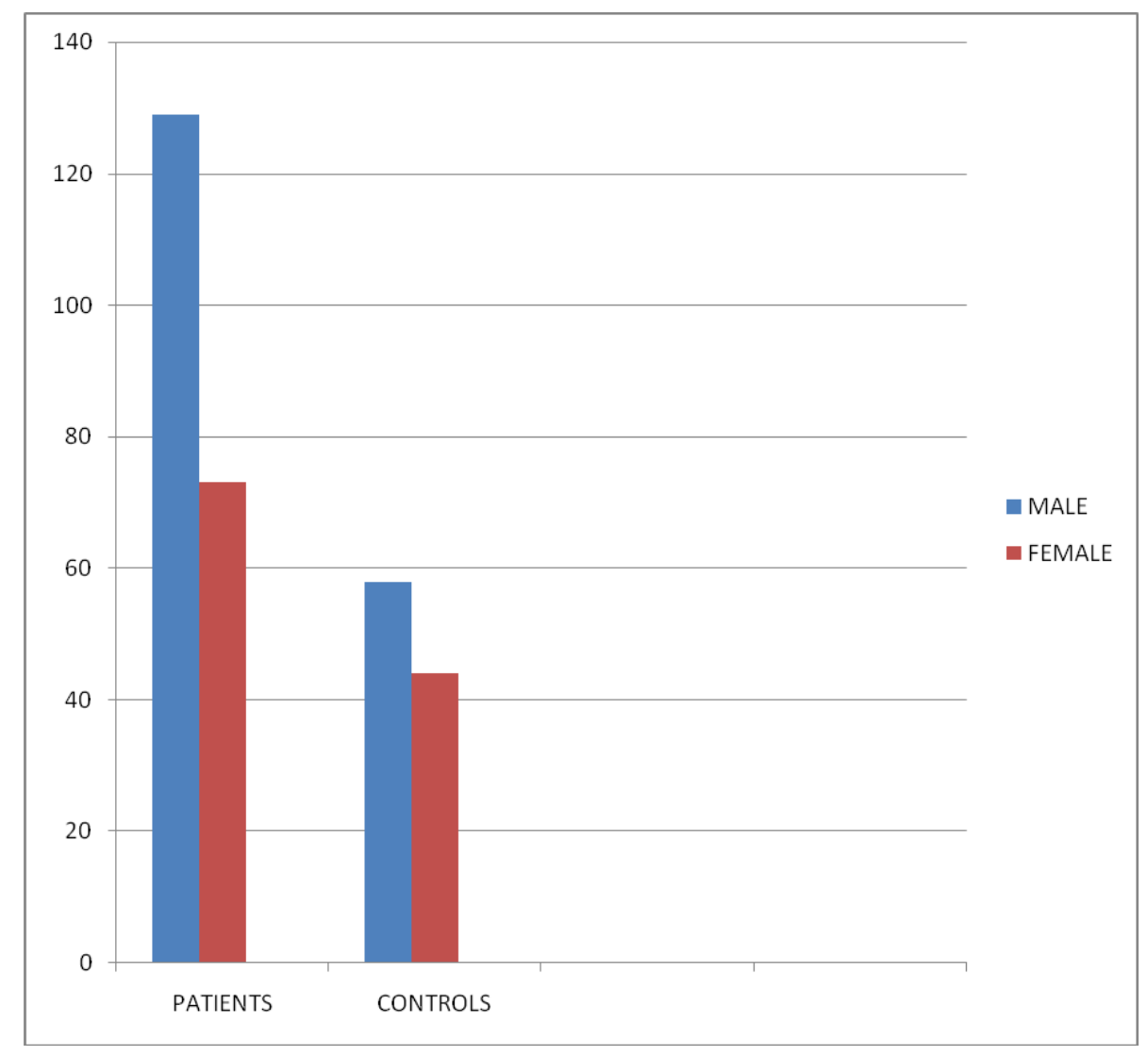

Figure 1. Sex distribution of malaria infected subjects and controls

Mean \pm SD of cortisol, MDA, glucose and HDL $24.18 \pm$ 4.19, $20.39 \pm 3.89,5.37 \pm 0.78$ and $29.85 \pm 4.36$ respectively in age group A were higher compared to other age groups; there is significant difference $(\mathrm{p}<0.05)$ observed in cortisol and glucose $\mathrm{F}=7.47, \mathrm{P}=0.00 ; \mathrm{F}=1.83$, $\mathrm{P}=0.12 ; \mathrm{F}=5.37, \mathrm{P}=0.00$ and $\mathrm{F}=0.39, \mathrm{P}=0.82$ respectively. Mean \pm SD of LDL, triglyceride and total cholesterol 58.59 \pm 15.12 , $85.29 \pm 22.90$ and $104.12 \pm 15.33$ respectively in age group $\mathrm{D}$ were higher compared to other age groups; there is significant difference $(\mathrm{P}<0.05)$ in triglyceride; $\mathrm{F}=0.87, \mathrm{P}=0.84 ; \mathrm{F}=2.83, \mathrm{P}=0.03$ and $\mathrm{F}=0.89, \mathrm{P}=0.47$ respectively. Multiple comparism between age group $\mathrm{A}$ and $B$ shows that age group A had higher Mean \pm SD of cortisol, MDA, glucose, HDL, LDL and total cholesterol compared to Mean \pm SD in age group $B$ while age group $B$ had higher Mean \pm SD of triglyceride compared to Mean \pm $\mathrm{SD}$ in age group $\mathrm{A}$; comparison shows no significant difference $(\mathrm{p}>0.05)$. Multiple comparism between age group $\mathrm{A}$ and $\mathrm{C}$ shows that age group $\mathrm{A}$ had higher Mean \pm SD of cortisol, MDA, glucose, HDL, LDL and total cholesterol compared to Mean \pm SD in age group $C$ while age group $C$ had higher Mean $\pm S D$ of triglyceride compared to Mean \pm SD in age group A; comparism shows significant difference $(\mathrm{p}<0.05)$ cortisol, glucose and triglyceride. Multiple comparism between age group $\mathrm{A}$ and $\mathrm{D}$ shows that age group A had higher Mean \pm SD of cortisol, MDA, glucose and HDL compared to Mean \pm SD in age group $\mathrm{D}$ while age group $\mathrm{D}$ had higher Mean \pm SD of LDL, triglyceride and total cholesterol compared to Mean \pm SD in age group A; comparism shows significant difference $(\mathrm{p}<0.05)$ in cortisol and glucose. Multiple comparison between age group $\mathrm{A}$ and $\mathrm{E}$ shows that age group A had higher Mean \pm SD of cortisol, MDA, glucose and HDL compared to Mean \pm SD in age group $\mathrm{E}$ while age group $\mathrm{E}$ had higher Mean \pm SD of LDL, triglyceride and total cholesterol compared to Mean \pm SD in age group $A$; comparism shows significant difference $(p<0.05)$ in cortisol, MDA and glucose. Multiple comparison between age group $\mathrm{B}$ and $\mathrm{C}$ shows that age group $\mathrm{B}$ had higher Mean \pm SD of cortisol, MDA, glucose, HDL and LDL compared to Mean \pm SD in age group $C$ while age group $C$ had higher Mean \pm SD of triglyceride and total cholesterol compared to Mean $\pm \mathrm{SD}$ in age group $\mathrm{B}$; comparison shows no significant difference $(p>0.05)$. Multiple comparism between age group $\mathrm{B}$ and $\mathrm{D}$ shows that age group $\mathrm{B}$ had higher mean $\pm \mathrm{SD}$ of cortisol, MDA, glucose and HDL compared to mean \pm SD in age group $\mathrm{D}$ while age group $\mathrm{D}$ had higher mean \pm SD of LDL, triglyceride and total cholesterol compared to mean \pm SD in age group $B$; Comparison shows no significant difference ( $p>0.05$ ). Multiple comparism between age group $\mathrm{B}$ and $\mathrm{E}$ shows that age group $\mathrm{B}$ had higher mean $\pm \mathrm{SD}$ of cortisol, MDA, glucose and HDL compared to mean \pm SD in age group $\mathrm{E}$ while age group $\mathrm{E}$ had higher mean $\pm \mathrm{SD}$ of LDL, triglyceride and total cholesterol compared to mean \pm SD in age group $\mathrm{B}$; Comparison shows no significant 
difference $(p>0.05)$. Multiple comparism between age group $\mathrm{C}$ and $\mathrm{D}$ shows that age group $\mathrm{C}$ had higher mean \pm SD of cortisol, glucose and HDL compared to mean \pm SD in age group $\mathrm{D}$ while age group $\mathrm{D}$ had higher mean $\pm \mathrm{SD}$ of MDA, LDL, triglyceride and total cholesterol compared to mean $\pm \mathrm{SD}$ in age group $\mathrm{C}$; Comparism shows no significant difference $(\mathrm{p}>0.05)$. Multiple comparism between age group $\mathrm{C}$ and $\mathrm{E}$ shows that age group $\mathrm{C}$ had higher mean \pm SD of cortisol, MDA, glucose, HDL and triglyceride compared to mean $\pm \mathrm{SD}$ in age group $\mathrm{E}$ while age group $\mathrm{E}$ had higher mean \pm SD of $\mathrm{LDL}$ and total cholesterol compared to mean $\pm \mathrm{SD}$ in age group $\mathrm{C}$; Comparison shows no significant difference $(p>0.05)$. Multiple comparism between age group $\mathrm{D}$ and $\mathrm{E}$ shows that age group $\mathrm{D}$ had higher mean \pm SD of MDA, glucose, LDL, triglyceride and total cholesterol compared to mean \pm SD in age group $E$ while age group $E$ had higher mean \pm SD of cortisol and HDL compared to mean \pm SD in age group D; Comparison shows no significant difference ( $\mathrm{p}>0.05)$ as shown in Table 1.

Table 1. MEAN \pm SD OF AGE DISTRIBUTION ON BIOCHEMICAL PARAMETERS IN PRE-TREATMENT ANTI-MALARIA DRUG IN MALARIA INFECTED SUBJECTS

\begin{tabular}{|c|c|c|c|c|c|c|c|}
\hline Groups & $\begin{array}{c}\text { Cortisol } \\
(\mu \mathrm{g} / \mathrm{dl})\end{array}$ & $\begin{array}{c}\text { MDA } \\
((\mathrm{nmol} / \mathrm{ml})\end{array}$ & $\begin{array}{c}\text { Glucose } \\
\mathrm{mmol} / \mathrm{L} \text { ) }\end{array}$ & $\begin{array}{l}\text { HDL } \\
\text { (mg/dl) }\end{array}$ & $\begin{array}{c}\text { LDL } \\
\text { (mg/dl) }\end{array}$ & $\begin{array}{c}\text { Trig } \\
\text { (mg/dl) }\end{array}$ & $\begin{array}{c}\begin{array}{c}\text { Total CHO } \\
(\mathrm{mg} / \mathrm{dl})\end{array} \\
\end{array}$ \\
\hline $\mathrm{A}(\mathrm{n}=68)$ & $24.18 \pm 4.19$ & $20.39 \pm 3.89$ & $5.37 \pm 0.78$ & $29.85 \pm 4.36$ & $54.04 \pm 14.19$ & $73.04 \pm 17.40$ & $98.49 \pm 12.96$ \\
\hline$B(n=59)$ & $22.64 \pm 2.99$ & $19.60 \pm 3.00$ & $5.19 \pm 0.76$ & $29.49 \pm 4.67$ & $51.75 \pm 18.99$ & $76.78 \pm 18.14$ & $96.61 \pm 19.49$ \\
\hline$C(n=34)$ & $21.17 \pm 3.26$ & $19.17 \pm 1.92$ & $4.94 \pm 0.70$ & $29.00 \pm 4.79$ & $50.76 \pm 15.01$ & $84.65 \pm 19.89$ & $96.62 \pm 14.80$ \\
\hline $\mathrm{D}(\mathrm{n}=17)$ & $20.6 \pm 2.54$ & $19.52 \pm 1.23$ & $4.76 \pm 0.62$ & $28.65 \pm 4.37$ & $58.59 \pm 15.12$ & $85.29 \pm 22.90$ & $104.12 \pm 15.33$ \\
\hline$E(n=24)$ & $21.09 \pm 3.18$ & $18.75 \pm 1.55$ & $4.71 \pm 0.69$ & $28.92 \pm 6.07$ & $54.58 \pm 15.38$ & $81.29 \pm 26.45$ & $99.83 \pm 15.30$ \\
\hline $\begin{array}{c}\mathrm{F} \\
\text { (p-value) }\end{array}$ & $\begin{array}{c}7.47 \\
(0.00) \\
\end{array}$ & $\begin{array}{c}1.83 \\
(0.12) \\
\end{array}$ & $\begin{array}{c}5.37 \\
(0.00) \\
\end{array}$ & $\begin{array}{c}0.39 \\
(0.82) \\
\end{array}$ & $\begin{array}{c}0.87 \\
(0.48) \\
\end{array}$ & $\begin{array}{c}2.83 \\
(0.03) \\
\end{array}$ & $\begin{array}{c}0.89 \\
(0.47) \\
\end{array}$ \\
\hline $\begin{array}{c}\text { AvsB } \\
\text { p-value }\end{array}$ & 0.12 & 0.69 & 0.68 & 1.00 & 0.94 & 0.76 & 0.97 \\
\hline $\begin{array}{c}\text { AvsC } \\
\text { p-value }\end{array}$ & 0.00 & 0.22 & 0.05 & 0.91 & 0.84 & 0.04 & 0.97 \\
\hline $\begin{array}{c}\text { AvsD } \\
\text { p-value }\end{array}$ & 0.00 & 0.53 & 0.02 & 0.85 & 0.79 & 0.27 & 0.64 \\
\hline $\begin{array}{c}\text { AvsE } \\
\text { p-value }\end{array}$ & 0.00 & 0.04 & 0.00 & 0.96 & 1.00 & 0.62 & 1.00 \\
\hline $\begin{array}{c}\text { BvsC } \\
\text { p-value }\end{array}$ & 0.21 & 0.92 & 0.50 & 0.99 & 1.00 & 0.33 & 1.00 \\
\hline $\begin{array}{c}\text { BvsD } \\
\text { p-value }\end{array}$ & 0.07 & 1.00 & 0.16 & 0.96 & 0.54 & 0.63 & 0.47 \\
\hline $\begin{array}{c}\text { BvsE } \\
\text { p-value }\end{array}$ & 0.26 & 0.45 & 0.06 & 0.99 & 0.95 & 0.94 & 0.93 \\
\hline $\begin{array}{c}\text { CvsD } \\
\text { p-value }\end{array}$ & 0.96 & 0.93 & 0.89 & 1.00 & 0.43 & 1.00 & 0.47 \\
\hline $\begin{array}{c}\text { CvsE } \\
\text { p-value }\end{array}$ & 1.00 & 0.89 & 0.74 & 1.00 & 0.89 & 0.98 & 0.93 \\
\hline $\begin{array}{c}\text { DvsE } \\
\text { p-value }\end{array}$ & 0.98 & 0.41 & 1.00 & 1.00 & 0.92 & 0.99 & 0.90 \\
\hline
\end{tabular}

N.B: $\mathrm{A}=(15-24), \mathrm{B}=(25-34), \mathrm{C}=(35-44), \mathrm{D}=(45-54), \mathrm{E}=(55-64)$

$\mathrm{P}<0.05$ significance, $\mathrm{P}>0.05$ no Significant, $\mathrm{F}$ ( $\mathrm{P}$-value) $=$ mean $\pm \mathrm{SD}$ of parameters compared using ANOVA

Mean \pm SD of cortisol, MDA and glucose $20.57 \pm 7.65$; SD of HDL and triglyceride compared to mean \pm SD in $18.15 \pm 7.41$ and $4.78 \pm 1.01$ respectively in age group $\mathrm{A}$ were higher compared to other age groups; It shows significant difference $(\mathrm{p}<0.05)$. $\mathrm{F}=12.34, \mathrm{P}=0.00 ; \mathrm{F}=8.64$, $\mathrm{P}=0.00$ and $\mathrm{F}=8.24, \mathrm{P}=0.00$ respectively. Mean $\pm \mathrm{SD}$ of HDL and triglyceride $27.56 \pm 3.27$ and $92.82 \pm 6.22$ respectively in age group $C$ were higher compared to other age groups; It shows significant difference $(\mathrm{P}<0.05)$ in triglyceride; $\mathrm{F}=0.03, \mathrm{P}=1.00 ; \mathrm{F}=3.21 \mathrm{P}=0.01$ respectively. Mean \pm SD of LDL and total cholesterol $62.47 \pm 9.59$ and $108.41 \pm 10.97$ respectively in age group D were higher compared to other age group. It shows no significant difference $(\mathrm{P}>0.05) ; \mathrm{F}=1.11, \mathrm{P}=0.35$ and $\mathrm{F}=0.99, \mathrm{P}=0.42$ respectively. Multiple comparism between age group $\mathrm{A}$ and $B$ shows that age group $A$ had higher mean \pm SD of cortisol, MDA, glucose, HDL, LDL and total cholesterol compared to mean \pm SD in age group $B$ while age group $B$ had higher mean \pm SD of triglyceride compared to mean \pm $\mathrm{SD}$ in age group $\mathrm{A}$; Comparison shows significant difference $(p<0.05)$ in cortisol, MDA and glucose. Multiple comparism between age group $\mathrm{A}$ and $\mathrm{C}$ shows that age group A had higher mean \pm SD of cortisol, MDA, glucose, LDL and total cholesterol compared to mean \pm $\mathrm{SD}$ in age group $\mathrm{C}$ while age group $\mathrm{C}$ had higher mean \pm age group $\mathrm{A}$; Comparism shows significant difference $(\mathrm{p}<0.05)$ in cortisol, MDA, glucose and triglyceride. Multiple comparism between age group $\mathrm{A}$ and $\mathrm{D}$ shows that age group A had higher mean \pm SD of cortisol, MDA, glucose, HDL, and total cholesterol compared to mean \pm SD in age group D while age group $\mathrm{D}$ had higher mean \pm SD of LDL and triglyceride compared to mean \pm SD in age group A; Comparism shows significant difference $(\mathrm{p}<0.05)$ in cortisol, MDA and glucose. Multiple comparism between age group $\mathrm{A}$ and $\mathrm{E}$ shows that age group $\mathrm{A}$ had higher mean \pm SD of cortisol, MDA, glucose, and HDL compared to mean $\pm \mathrm{SD}$ in age group $\mathrm{E}$ while age group $\mathrm{E}$ had higher mean \pm SD of LDL, triglyceride and total cholesterol compared to mean $\pm \mathrm{SD}$ in age group $\mathrm{A}$; Comparison shows significant difference $(p<0.05)$ in cortisol, MDA and glucose. Multiple comparism between age group $\mathrm{B}$ and $\mathrm{C}$ shows that age group $\mathrm{B}$ had higher mean \pm SD of cortisol, MDA, glucose, LDL and total cholesterol compared to mean \pm SD in age group $\mathrm{C}$ while age group $\mathrm{C}$ had higher mean $\pm \mathrm{SD}$ of $\mathrm{HDL}$ and triglyceride compared to mean $\pm \mathrm{SD}$ in age group $\mathrm{B}$; Comparism shows no significant difference $(p<0.05)$. Multiple comparism between age group $\mathrm{B}$ and $\mathrm{D}$ shows 
that age group B had higher mean \pm SD of cortisol, MDA, glucose and HDL compared to mean \pm SD in age group $\mathrm{D}$ while age group $\mathrm{D}$ had higher mean \pm SD of LDL, triglyceride and total cholesterol compared to mean \pm SD in age group $\mathrm{B}$; Comparism shows significant difference $(\mathrm{p}<0.05)$ in MDA and glucose. Multiple comparism between age group $\mathrm{B}$ and $\mathrm{E}$ shows that age group $\mathrm{B}$ had higher mean \pm SD of cortisol, MDA, and glucose compared to mean $\pm \mathrm{SD}$ in age group $\mathrm{E}$ while age group $\mathrm{E}$ had higher mean \pm SD of HDL, LDL, triglyceride and total cholesterol compared to mean \pm SD in age group $\mathrm{B}$; Comparism shows no significant difference ( $p>0.05)$. Multiple comparism between age group $\mathrm{C}$ and $\mathrm{D}$ shows that age group $\mathrm{C}$ had higher mean $\pm \mathrm{SD}$ of cortisol, MDA, glucose, HDL, and triglyceride compared to mean \pm SD in age group $\mathrm{D}$ while age group $\mathrm{D}$ had higher mean $\pm \mathrm{SD}$ of
LDL and total cholesterol compared to mean \pm SD in age group C; Comparism shows no significant difference ( $>0.05$ ). Multiple comparism between age group $\mathrm{C}$ and $\mathrm{E}$ shows that age group $\mathrm{C}$ had higher mean $\pm \mathrm{SD}$ of cortisol, MDA, glucose, HDL and Triglyceride compared to mean \pm $\mathrm{SD}$ in age group $\mathrm{E}$ while age group $\mathrm{E}$ had higher mean \pm SD of LDL and total cholesterol compared to mean \pm SD in age group $\mathrm{C}$. Comparism shows no significant difference $(\mathrm{P}>0.05)$. Multiple comparison between age group $\mathrm{D}$ and $\mathrm{E}$ shows that age group $\mathrm{D}$ had higher mean \pm SD of glucose, MDA, LDL triglyceride and total cholesterol compared to mean \pm SD in age group $\mathrm{E}$ while age group $\mathrm{E}$ had higher mean $\pm \mathrm{SD}$ of cortisol, and HDL compared to mean $\pm \mathrm{SD}$ in age group $\mathrm{D}$; Comparism shows no significant difference $(\mathrm{P}>0.05)$ as shown in Table 2.

Table 2. MEAN \pm SD OF AGE DISTRIBUTION ON BIOCHEMICAL PARAMETERS IN POST ANTI-MALARIA DRUG TREATMENT IN MALARIA INFECTED SUBJECTS

\begin{tabular}{|c|c|c|c|c|c|c|c|}
\hline Groups & Cortisol ( $\mu \mathrm{g} / \mathrm{dl})$ & $\begin{array}{c}\text { MDA } \\
((\mathrm{nmol} / \mathrm{ml})\end{array}$ & $\begin{array}{c}\text { Glucose } \\
(\mathrm{mmol} / \mathrm{L})\end{array}$ & $\begin{array}{c}\text { HDL } \\
\text { (mg/dl) }\end{array}$ & $\begin{array}{c}\text { LDL } \\
\text { (mg/dl) }\end{array}$ & $\begin{array}{c}\text { Trig } \\
\text { (mg/dl) }\end{array}$ & $\begin{array}{c}\text { Total CHO } \\
\text { (mg/dl) }\end{array}$ \\
\hline$A n=68)$ & $20.57 \pm 7.65$ & $18.15 \pm 7.41$ & $4.78 \pm 1.01$ & $27.53 \pm 3.50$ & $59.38 \pm 11.44$ & $81.65 \pm 15.22$ & $103.26 \pm 10.62$ \\
\hline$B(n=59)$ & $15.86 \pm 5.13$ & $14.81 \pm 4.28$ & $4.29 \pm 0.66$ & $27.37 \pm 3.51$ & $57.61 \pm 14.42$ & 86.7517 .10 & $102.32 \pm 14.95$ \\
\hline$C(n=34)$ & $15.19 \pm 4.81$ & $13.62 \pm 3.70$ & $4.26 \pm 0.81$ & $27.56 \pm 3.27$ & $55.76 \pm 11.40$ & $92.82 \pm 6.22$ & $102.00 \pm 10.98$ \\
\hline $\mathrm{D}(\mathrm{n}=17)$ & $13.13 \pm 3.44$ & $12.09 \pm 1.70$ & $3.82 \pm 0.48$ & $27.35 \pm 2.76$ & $62.47 \pm 9.59$ & $92.71 \pm 19.54$ & $108.41 \pm 10.97$ \\
\hline$E(n=24)$ & $12.85 \pm 4.25$ & $13.16 \pm 2.68$ & $3.97 \pm 0.68$ & $27.46 \pm 4.00$ & $59.75 \pm 10.87$ & $89.54 \pm 22.10$ & $104.62 \pm 12.23$ \\
\hline $\begin{array}{c}F \\
\text { (p-value) }\end{array}$ & $\begin{array}{l}12.34 \\
(0.00)\end{array}$ & $\begin{array}{c}8.64 \\
(0.00)\end{array}$ & $\begin{array}{c}8.24 \\
(0.00)\end{array}$ & $\begin{array}{c}0.03 \\
(1.00)\end{array}$ & $\begin{array}{c}1.11 \\
(0.35)\end{array}$ & $\begin{array}{c}3.21 \\
(0.01)\end{array}$ & $\begin{array}{c}0.99 \\
(0.42)\end{array}$ \\
\hline $\begin{array}{c}\text { AvsB } \\
\text { p-value }\end{array}$ & 0.00 & 0.02 & 0.01 & 1.00 & 0.94 & 0.40 & 0.99 \\
\hline $\begin{array}{c}\text { AvsC } \\
\text { p-value }\end{array}$ & 0.00 & 0.0 .0 & 0.03 & 1.00 & 0.56 & 0.01 & 0.98 \\
\hline $\begin{array}{c}\text { AvsD } \\
\text { p-value }\end{array}$ & 0.00 & 0.00 & 0.00 & 1.00 & 0.78 & 0.23 & 0.43 \\
\hline $\begin{array}{c}\text { AvsE } \\
\text { p-value }\end{array}$ & 0.00 & 0.00 & 0.00 & 1.00 & 1.00 & 0.50 & 0.99 \\
\hline $\begin{array}{c}\text { BvsC } \\
\text { p-value }\end{array}$ & 0.97 & 0.63 & 1.00 & 1.00 & 0.96 & 0.44 & 1.00 \\
\hline $\begin{array}{c}\text { BvsD } \\
\text { p-value }\end{array}$ & 0.10 & 0.00 & 0.02 & 1.00 & 0.49 & 0.79 & 0.36 \\
\hline $\begin{array}{c}\text { BvsE } \\
\text { p-value }\end{array}$ & 0.06 & 0.23 & 0.29 & 1.00 & 0.95 & 0.98 & 0.95 \\
\hline $\begin{array}{c}\text { CvsD } \\
\text { p-value }\end{array}$ & 0.41 & 0.27 & 0.18 & 1.00 & 0.19 & 1.00 & 0.30 \\
\hline $\begin{array}{c}\text { CvsE } \\
\text { p-value }\end{array}$ & 0.30 & 0.98 & 0.68 & 1.00 & 0.66 & 0.97 & 0.92 \\
\hline $\begin{array}{c}\text { DvsE } \\
\text { p-value }\end{array}$ & 1.00 & 0.53 & 0.92 & 1.00 & 0.91 & 0.99 & 0.84 \\
\hline
\end{tabular}

N.B: $A=(15-24), B=(25-34), C=(35-44), D=(45-54), E=(55-64)$

$\mathrm{P}<0.05$ significance, $\mathrm{P}>0.05$ no Significant, $\mathrm{F}(\mathrm{P}$-value $)=$ mean \pm SD of parameters compared using ANOVA.

Mean \pm SD of cortisol, MDA, glucose, HDL, group A and C shows that age group A had higher mean triglyceride and total cholesterol, $8.20 \pm 0.90,9.10 \pm 0.40$, $3.70 \pm 0.35,44.67 \pm 1.53,113.33 \pm 11.06$ and $134.67 \pm 5.51$ respectively in age group $\mathrm{E}$ were higher compared to mean $\pm \mathrm{SD}$ in other age groups. It shows significant difference $(\mathrm{P}<0.05)$ in cortisol, MDA, triglyceride and total cholesterol. $\mathrm{F}=7.46, \mathrm{P}=0.00 ; \mathrm{F}=4.77, \mathrm{P}=0.00 ; \mathrm{F}=0.40$, $\mathrm{P}=0.81 ; \mathrm{F}=2.23, \mathrm{P}=0.07 ; \mathrm{F}=3.76, \mathrm{P}=0.01$ and $\mathrm{F}=7.47$, $\mathrm{P}=0.00$ respectively. Mean \pm SD of LDL 66.42 \pm 5.89 in age group $\mathrm{C}$ was higher compared to mean $\pm \mathrm{SD}$ in other age groups, it shows significant difference $(\mathrm{P}<0.05) \mathrm{F}=6.25$, $\mathrm{P}=0.00$. Multiple comparison between age group $\mathrm{A}$ and $\mathrm{B}$ shows that age group A had higher mean \pm SD of MDA, and glucose compared to mean $\pm \mathrm{SD}$ in age group $\mathrm{B}$ while age group B had higher mean \pm SD of cortisol, HDL, LDL, triglyceride, and total cholesterol compared to mean \pm SD in age group $\mathrm{A}$; comparism shows no significant difference $(\mathrm{P}>0.05)$. Multiple comparison between age $\pm \mathrm{SD}$ of glucose compared to mean $\pm \mathrm{SD}$ in age group $\mathrm{C}$ while age group $C$ had higher mean \pm SD of cortisol, MDA, HDL, LDL, triglyceride and total cholesterol compared to mean \pm SD in age group A. Comparism shows significant difference $(\mathrm{P}<0.05)$ in cortisol, LDL and total cholesterol. Multiple comparison between age group $\mathrm{A}$ and $\mathrm{D}$ shows that age group $\mathrm{A}$ had higher mean $\pm \mathrm{SD}$ of glucose compared to mean \pm SD in age group $\mathrm{D}$ while age group $\mathrm{D}$ had higher mean \pm SD of cortisol, MDA, HDL, LDL, triglyceride and total cholesterol compared to mean \pm SD in age group $\mathrm{A}$; comparism shows significant difference $(\mathrm{P}<0.05)$ in cortisol, LDL, and total cholesterol. Multiple comparison between age group $\mathrm{A}$ and $\mathrm{E}$ shows that age group E had higher mean \pm SD of cortisol, MDA, glucose, HDL, LDL, triglyceride and total cholesterol compared to mean $\pm \mathrm{SD}$ in age group $\mathrm{A}$; comparism shows no significant difference $(\mathrm{P}>0.05)$. Multiple comparison 
between age group $\mathrm{B}$ and $\mathrm{C}$ shows that age group $\mathrm{C}$ had higher mean \pm SD of cortisol, MDA, glucose, HDL, LDL, triglyceride and total cholesterol compared to mean \pm SD in age group $\mathrm{B}$; comparism shows no significant difference $(\mathrm{P}>0.05)$. Multiple comparison between age group $\mathrm{B}$ and $\mathrm{D}$ shows that age group $\mathrm{D}$ had higher mean \pm SD of cortisol, MDA, glucose, HDL, LDL, triglyceride and total cholesterol compared to mean \pm SD in age group $B$; comparism shows significant difference $(\mathrm{P}<0.05)$ in MDA. Multiple comparison between age group $\mathrm{B}$ and $\mathrm{E}$ shows that age group $\mathrm{E}$ had higher mean \pm SD of cortisol, MDA, glucose, HDL, LDL, triglyceride and total cholesterol compared to mean \pm SD in age group $\mathrm{B}$; comparism shows no significant difference $(\mathrm{P}>0.05)$. Multiple comparison between age group $\mathrm{C}$ and $\mathrm{D}$ shows that age group $\mathrm{C}$ had higher mean $\pm \mathrm{SD}$ of cortisol, MDA, glucose and LDL compared to mean \pm SD in age group $\mathrm{D}$ while age group $\mathrm{D}$ had higher mean \pm SD of HDL, triglyceride, and total cholesterol compared to mean $\pm \mathrm{SD}$ in age group $\mathrm{C}$; comparism shows no significant difference $(\mathrm{P}>0.05)$. Multiple comparison between age group $\mathrm{C}$ and $\mathrm{E}$ shows that age group $\mathrm{E}$ had higher mean \pm SD of cortisol, MDA, glucose, HDL, triglyceride and total cholesterol compared to mean \pm SD in age group $\mathrm{C}$ while age group $\mathrm{C}$ had mean \pm SD of LDL compared to mean \pm $\mathrm{SD}$ in age group $\mathrm{E}$; comparism shows no significant difference $(\mathrm{P}>0.05)$. Multiple comparison between age group $\mathrm{D}$ and $\mathrm{E}$ shows that age group $\mathrm{E}$ had higher mean \pm SD of cortisol, MDA, glucose, HDL, LDL, triglyceride and total cholesterol compared to mean \pm SD in age group $\mathrm{D}$; comparism shows significant difference $(\mathrm{P}>0.05)$.

Table 3. MEAN \pm SD OF AGE DISTRIBUTION ON BIOCHEMICAL PARAMETERS IN NON-MALARIA INFECTED SUBJECTS (CONTROLS)

\begin{tabular}{|c|c|c|c|c|c|c|c|}
\hline Groups & $\begin{array}{c}\text { Cortisol } \\
\text { ( } \mu \text { g/dl) }\end{array}$ & $\begin{array}{c}\text { MDA } \\
((\mathrm{nmol} / \mathrm{ml})\end{array}$ & $\begin{array}{c}\text { Glucose } \\
(\mathrm{mmol} / \mathrm{L})\end{array}$ & $\begin{array}{c}\text { HDL } \\
\text { (mg/dl) }\end{array}$ & $\begin{array}{c}\text { LDL } \\
\text { (mg/dl) }\end{array}$ & $\begin{array}{c}\text { Trig } \\
\text { (mg/dl) }\end{array}$ & $\begin{array}{c}\text { Total CHO } \\
(\mathrm{mg} / \mathrm{dl})\end{array}$ \\
\hline$A(n=68)$ & $5.78 \pm 1.32$ & $8.15 \pm 0.90$ & $3.65 \pm 0.32$ & $41.14 \pm 3.41$ & $58.89 \pm 5.88$ & $92.25 \pm 9.29$ & $118.17 \pm 7.85$ \\
\hline$B(n=59)$ & $6.18 \pm 1.76$ & $7.81 \pm 0.83$ & $3.50 \pm 0.34$ & $41.45 \pm 3.62$ & $62.15 \pm 7.62$ & $96.90 \pm 13.45$ & $123.05 \pm 11.20$ \\
\hline$C(n=34)$ & $7.53 \pm 1.38$ & $8.65 \pm 0.73$ & $3.57 \pm 0.30$ & $42.38 \pm 3.21$ & $66.42 \pm 5.89$ & $98.42 \pm 10.49$ & $128.38 \pm 9.07$ \\
\hline $\mathrm{D}(\mathrm{n}=17)$ & $7.16 \pm 1.44$ & $8.64 \pm 0.77$ & $3.56 \pm 0.36$ & $43.74 \pm 2.37$ & $65.21 \pm 4.94$ & $100.01 \pm 11.89$ & $129.00 \pm 96.67$ \\
\hline$E(n=24)$ & $8.20 \pm 0.90$ & $9.10 \pm 0.40$ & $3.70 \pm 0.35$ & $44.67 \pm 1.53$ & $64.00 \pm 11.53$ & $113.33 \pm 11.06$ & $134.67 \pm 5.51$ \\
\hline $\begin{array}{c}\mathrm{F} \\
\text { (p-value) }\end{array}$ & $\begin{array}{c}7.46 \\
(0.00)\end{array}$ & $\begin{array}{c}4.77 \\
(0.00)\end{array}$ & $\begin{array}{c}0.40 \\
(0.81)\end{array}$ & $\begin{array}{c}2.23 \\
(0.07)\end{array}$ & $\begin{array}{c}6.25 \\
(0.00)\end{array}$ & $\begin{array}{c}3.76 \\
(0.01)\end{array}$ & $\begin{array}{c}7.47 \\
(0.00)\end{array}$ \\
\hline $\begin{array}{c}\text { AvsB } \\
\text { p-value }\end{array}$ & 0.90 & 0.61 & 0.98 & 0.99 & 0.47 & 0.65 & 0.43 \\
\hline $\begin{array}{c}\text { AvsC } \\
\text { p-value }\end{array}$ & 0.00 & 0.14 & 0.86 & 0.62 & 0.00 & 0.15 & 0.00 \\
\hline $\begin{array}{c}\text { AvsD } \\
\text { p-value }\end{array}$ & 0.01 & 0.23 & 0.88 & 0.19 & 0.00 & 0.12 & 0.00 \\
\hline $\begin{array}{c}\text { AvsE } \\
\text { p-value }\end{array}$ & 0.09 & 0.11 & 0.99 & 0.12 & 0.92 & 0.22 & 0.08 \\
\hline $\begin{array}{c}\text { BvsC } \\
\text { p-value }\end{array}$ & 0.06 & 0.01 & 0.99 & 0.90 & 0.27 & 0.99 & 0.44 \\
\hline $\begin{array}{c}\text { BvsD } \\
\text { p-value }\end{array}$ & 0.32 & 0.02 & 0.99 & 0.40 & 0.57 & 0.93 & 0.40 \\
\hline $\begin{array}{c}\text { BvsE } \\
\text { p-value }\end{array}$ & 0.13 & 0.34 & 0.98 & 0.16 & 0.99 & 0.34 & 0.15 \\
\hline $\begin{array}{c}\text { CvsD } \\
\text { p-value }\end{array}$ & 0.92 & 1.00 & 1.00 & 0.79 & 0.95 & 0.98 & 0.99 \\
\hline $\begin{array}{c}\text { CvsE } \\
\text { p-value }\end{array}$ & 0.79 & 0.51 & 0.96 & 0.36 & 0.99 & 0.39 & 0.52 \\
\hline $\begin{array}{c}\text { DvsE } \\
\text { p-value }\end{array}$ & 0.53 & 0.57 & 0.95 & 0.95 & 1.00 & 0.47 & 0.63 \\
\hline
\end{tabular}

N.B: $A=(15-24), B=(25-34), C=(35-44), D=(45-54), E=(55-64)$

$\mathrm{P}<0.05$ significance, $\mathrm{P}>0.05$ no Significant, $\mathrm{F}(\mathrm{P}$-value $)=$ mean $\pm \mathrm{SD}$ of parameters compared using ANOVA

\section{Discussion}

During malaria infection, a direct relationship between the release of cortisol and disease severity had been documented [23]. Tim et al., 1998 demonstrates higher serum cortisol level in acute stage of malaria infection than corresponding convalescent levels [24]. Inamo et al., 1991 reported a two - fold increase in cortisol levels during febrile of malaria infection which is consistent with findings in this study. This present study shows the relation between malaria-induced stress and the level of cortisol; cortisol levels were increased with the increase of the degree of parasitemia and reach significant levels in heavy infection [25]. Similar to this study, Resumo, 1998 reported that when persons experience stress, bodies release cortisol. He also reported that levels of cortisol in serum sample collected from malaria patients were significantly higher than those of normal subjects. He concluded that corticosteroid may interfere with initial response of $P$. falciparum-infected patients to treatment [26]. Hilary, 2002 supported this present study with the fact that infection with $P$. falciparum malaria increases the secretion of pro-inflammatory hormones and mediators which induce resistance to cortisol, such as tumour necrosis factors (TNFs) and antimicrobial agents, also the infection reduce the synthesis of cortisol receptors that increase plasma cortisol level [27]. It is also well known that the degree of parasitemia has effects on the immune system [28]. Similar to this study, young adult presented higher malondialdehyde level than the old in malaria infected patients. Akanbi et al., 2010 reported the highest parasite density was found among those within the age 
range 18-21 years while it was least among those within the older age. He then concluded that this could be due to the number of exposure to mosquito bites among older age people as it has been reported that the number of exposure to mosquito bite increases with age [29]. Thus, in agreement to the higher malondialdehyde level among the young than the old; the number of exposure to mosquito bites by individuals had been confirmed to increase the level of immunity against malaria infection [30] and these increases with age. Hence, in Plasmodium falciparum endemic areas, protective immunity against malaria infection is acquired slowly after a large number of infections and its maintenance requires a sustained exposure to infected mosquito [31]. The level of immunity against malaria has also been related to age of the individuals living in malaria endemic areas [32]. The glucose metabolism during malaria infection is affected by several factors, including drug treatment, fever, parasite metabolism, hormonal changes, cytokines, fasting and gastrointestinal disturbances [33]. Supporting the findings in this present study, Woodrow et al., 1999 stated that during malaria parasite infection, glucose is rapidly taken up across the parasite plasma membrane through a facilitated hexose transporter and is in turn metabolized through the process of glycolysis [34]. The Plasmodium falciparum parasites fully depend on glucose as an energy source; decrease in blood glucose level occurs during the management of patients with malaria, it is well known that anti-malaria drug stimulates diabetes relevant parameters, such as increased plasma insulin concentrations and hypoglycaemia. Davis et al., 1993 reported that in adults with severe malaria infection, blood glucose production was increased by $50 \%$ compared to convalescence [35]. Increased glucose production in malaria infection especially in severe or in cerebral malaria was entirely dependent on gluconeogenesis. In non-severe malaria, glucose production is increased by approximately $25 \%$, and gluconeogenesis contributes approximately $87 \%$ to total glucose production [36]. Cytokines, counter-regulatory hormones and precursor supply are all potentially implicated in the regulation of glucose production in malaria infection. High plasma cortisol may stimulate gluconeogenesis in humans [37] increase in plasma blood glucose concentration supports the idea of a major role for cortisol in the stimulation of gluconeogenesis in patients with malaria. However, increase in plasma cortisol associated with a major stimulation of gluconeogenesis in the patients with non-severe malaria [36]. The plasma blood glucose concentration is the result of glucose production and glucose uptake. Malaria often results in metabolic acidosis, mainly because the parasite while destroying red blood cells efficiently causes severe anaemia which in turn causes low oxygen tension. Thus, Lactate production builds up within the cell to eventually cause a drop in $\mathrm{pH}$, which in turn could develop into metabolic acidosis. This drop in plasma $\mathrm{pH}$ was observed in all the treated groups in varying degrees. Reduction in plasma $\mathrm{pH}$ below 7.4 could result in fatal outcomes due to metabolic acidosis [38]. Contrary to this present study, Kayode et al., 2011 indicated hypoglycemia in both malaria and typhoid co-infected patients. They posited that the level of hypoglycemia correlated with severity of infection, which was elicited by hyper-secretion of insulin [39]. Their report corroborates the studies by Onyesom and Agho 2011, who noted the incidence of hypoglycemia in malaria patients in Edo-Delta state [40]. The role of low serum insulin-like growth factor-1 (IGF-1) and low blood glucose levels in malaria infection was reported by Mizushima et al., 1994. They noted that $P$. falciparum infected patients with low IGF-1 levels (< $50 \mathrm{ng} / \mathrm{ml}$ ) presented hypoglycemia compared to other study groups [41]. In another study, Binh et al., 1997 reported the relative contribution of insulin-mediated and non-insulinmediated plasma glucose levels in severe malaria [42]. The report stated that there was a corresponding increase risk of hypoglycemia as infection progressed because host glucose production becomes insufficient for host/parasite demand. The study also revealed that basal plasma blood glucose increased in uncomplicated malaria because of peripheral insulin resistance which is similar to this present study. Moderate malaria infection caused significant reduction in serum fasting blood sugar (FBS) levels with blood sugar levels tending towards hypoglycemia ([FBS] $<60 \mathrm{mg} / \mathrm{dl}$ ). Lipid profile in this study is lower in malaria infected patients compared to controls, findings in this study was supported with the facts that rapidly growing malaria parasite requires large amounts of lipids for increase in surface area and volume of its internal membranes, certain serum lipid fractions may favour the onset and/or severity of malaria infection. Contrary to this present study, hypercholesterolemia and hypertriglyceridemia was observed in both uncomplicated and complicated malaria [35,43,44], whereas Kittl et al., 1992 have shown no correlation between severity of malaria attacks and extent of HDL - cholesterol decrease. Human serum HDL is necessary for $P$. falciparum in invitro culture [45]. However, it has been reported that HDL can be toxic for the parasite at high concentrations [46]. Imrie et al, 2004 have reported that in the absence of serum HDL in low concentration $(0.75 \mathrm{mg} / \mathrm{ml})$ supported growth of $P$. falciparum in vitro, whereas at high concentration (3 $\mathrm{mg} / \mathrm{ml}$ ), it was toxic to the parasite [47]. However, the evidence of higher concentrations of serum lipids in the infected group despite the requirement of lipids for the growth of the parasite, could be explained from the findings which suggested that the plasmodium genome contains genes encoding enzymes of phospholipids metabolism, allowing de novo synthesis of phosphatidy choline through the kneddy pathway and necessitating only the uptake of the small choline molecule [48]. In addition, the genome of the parasite contains genes similar to those for type II fatty acid synthesis pathway. The protein products of these genes are located within the apicoplast and allow for the production of fatty acids, some of which are unique to the parasite [49]. Thus the parasite may be able to meet many of its lipid requirements from its own biosynthetic pathways, although some extracellular lipids are necessary for in vitro growth. It has also been seen that plasma membrane cholesterol plays a role in the pathogenesis of immune evasion and clinical manifestations of falciparum malaria [50]. Lipids have been observed to play important roles in pathological changes observed in disease conditions and are implicated in the production of immunity against diseases [51]. Although the source of increase in erythrocyte lipid component in malaria infection is not from lipid of the parasite there is no indication that the increase in the serum lipid is due to the lipid content of the parasite [52]. 


\section{Conclusion}

The level of stress induced by malaria parasite is corresponded to the severity of infection and age differences; this could be due to the number of exposure to mosquito bites which increases with age and also increase the level of immunity against malaria infection. Thus, in Plasmodium falciparum endemic areas like ours, protective immunity against malaria infection is acquired slowly as the age is increasing after a large number of infections and its maintenance requires a sustained exposure to infected mosquito.

\section{References}

[1] UNICEF (2000). Rolling back malaria goals. A United Nation Children's Fund document. 2000; 16pp.

[2] Alaribe AAA, Ejekie GC, Ezedinachi ENU (2006). The ecology of Bain BJ (1996). Ethnic and sex differences in the total and differential white cell count and platelet count. J Clin Pathol. 49: 664-666.

[3] FMOH, 1990. Federal Republic of Nigeria Guidelines for Malaria Control. 1990; Pp 24.

[4] Das, B.S., J.K. Patnaik, S. Mohanty, S.K. Mishra, D. Mohanty, S.K. Satpathy and T.K. Bose, (1993). Plasma antioxidants and lipid peroxidation products in falciparum malaria. Am. J. Trop. Med. Hyg., 49: 720-725.

[5] Sibmooh N, Pipitaporn B, Wilairatana P, Dangdoungjai J, Udomsangpetch R, Looareesuwan S, Chantharaksri U: (2000) Effect of artemisinin on lipid peroxidation and fluidity of the erythrocyte membrane in malaria. Biol Pharm Bull, 23:1275-1280.

[6] Atamma H, Ginsburg H (1993): Origin of reactive oxygen species in erythrocytes Infected with Plasmodium falciparum. Mol Biochem Parasitol, 61:231-242.

[7] Akanbi, O.M., A.B. Odaibo and O.G. Ademowo, (2009). AntiMSP1 (19) antibody (IgG) and reactive oxygen species (ROS) response against malaria infection in pregnancy in South Western Nigeria. Asian Pacific J. Trop. Med., 2: 9-15.

[8] Farombi, E.O., Y.Y. Shyntum and G.O. Emerole, (2003). Influence of chloroquine Treatment and plasmodium falciparum infection on some enzymatic and non-enzymatic ntioxidant defense indices in human. Drug Chem. Toxicol., 26: 59-71.

[9] Sibmooh, N., Yamanont, P., Krudsood, S., Leowattana, W. Brittenham, G., Looareesuwan, S.and Udomsangpetch, R. (2004). Increased fluidity and oxidation of malarial lipoproteins: relation with severity and induction of endothelial expression of adhesion molecules. Lipids in Health and Disease. 3, 15.

[10] Egwunyenga, A.O., G. Isamah and O.P. Nmorsi, (2004). Lipid peroxidation and ascorbic acid levels in Nigeria children with acute falciparum malaria. Afr. J. Biotech., 3: 560-563.

[11] Hunt N.H. and R. Stocker, 1990. Oxidative stress and the redox status of malaria-infected erythrocytes. Blood Cell, 16: 499-526.

[12] Braga AC, Oliveira MBN, Feliciano GD, Reininger IW, Oliveira JF, Silva CR, Bernardo-Filho M (2000).The effect of drugs on the labeling of blood elements with Technetium. Curr Pharm Des. 6(11): 1179-1191.

[13] Anosike EO, Uwakwe AA, Monanu M, Ekeke GI (1991).Studies on human erythrocyte glutathione-S transferase from HbAA, HbAS and HbSS subjects Biochem. Biomed. Acta. 50:1051-1055.

[14] Pigeolet, E., P. Corbisier, A. Houbion, D. Lambert and C. Michiels et al., 1990. Glutathione peroxidase, superoxide dismutase and catalase inactivation by peroxides and oxygen derived free radicals. Mech. Ageing Dev., 51: 283-297.

[15] Guha, M., S. Kumar, V. Choubey, P Maity and U. Bandyopadhyay, (2006). Apoptosis in liver during malaria: Role of oxidative stress and implication of mitochondrial pathway. FASEB J., 7: 1224-1226.

[16] Dubey ML, Weingken C, Ganguly NK, Mahajan RC (1999). Comparative evaluation of methods of malaria parasite density determination in blood samples from patients and experimental animals. Indian J Med Res; 109: 20-7.

[17] Monica Cheesbrough (2005). Discrete Laboratory Practice in Tropical Countries Part 1, Cambridge Second Editions. Published by Press Syndicate of the University of Cambridge, chp. 5, page 247-258.

[18] Dayachi F, Kabongo L, Ngoie K. Decreased mortality from Malaria in children with symptomatic HIV infection. Int. Cont. AIDS (1991) 2: 164.

[19] Warhurst, D.C. and J.E. Williams,. Acp Broadsheet no 148. July 1996. Laboratory diagnosis of malaria. J. Clin. Pathol., (1996) 49: 533-538.

[20] Dib M, Garrel C, Favier A, Robin V, Desnuelle C. (2002). Can malondialdehyde be used as a biological marker of progression in neurodegenerative disease? J Neurol; 249: 367-74.

[21] Nurten Tüközkan, Hüsamettin Erdamar, Ilgım Seven (2006) Measurement of Total Malondialdehyde in Plasma and Tissues by High-Performance Liquid Chromatography and Thiobarbituric Acid Assay Firat Tip Dergisi; 11(2): 88-92.

[22] Pilz J, Meineke I, Gleiter CH 2000. Measurement of free and bound malondialdehyde in plasma by high-performance liquid chromatography as the 2,4-dinitrophenylhydrazine derivative. $J$ Chromatogr B Biomed Sci Appl; 742: 315-25.

[23] Baster J D, Tyrrell J B (1981). The adrenal cortex In: felig P Baster J D, Broadus A E, Frohman L A eds Endocrinology and Metabolism $2^{\text {nd }}$ ed London Mc Graw- Hill: 529-530.

[24] Tim Shwe, Myo Khin, Hia Mim, Koko Hia, Yin Yin Win, Kyin Htwe, and Thein Myint Thu (1998) Serum cortisol levels in patients with uncomplicated and cerebral malaria vol. 29 No 1: 1-4

[25] Inamo $Y$, Iakeuchi S, Okuni M, (1991) Host responses and neuroendocrinological changes in pyrexia in childhood. Acta pacdiat jpn (overseas ed) 33: 628-632.

[26] Resumo DT (1998). Evaluation of both cortisol and dehidroepiondrosterone levels in Patients with non-complicated malaria due to plasmodium falciparum Soc. Bra. Med. Trop. 13 (2): $243-244$.

[27] Hilary T (2002). Sex hormones' link to stress. UBC reports 48(5).

[28] Deans JA, Scohen (1983). Immunology of malaria. Ann. Rev. Microbiol. 37: 25-49.

[29] Akanbi, O.M., J.A. Badaki, O.Y. Adeniran and O.O. Olotu, (2010). Effect of blood group and demographic characteristics on malaria infection, oxidative stress and haemoglobin levels in South Western Nigeria. Afr. J. Microbiol. Res., 4: 877-880.

[30] Hommel, M., 1991. Steps towards a malaria vaccine. Res. Immunol., 142: 618-631.

[31] Akanbi, O.M., A.B. Odaibo and O.G. Ademowo, (2009). AntiMSP1 (19) antibody (IgG) and reactive oxygen species (ROS) response against malaria infection in pregnancy in South Western Nigeria. Asian Pacific J. Trop. Med., 2: 9-15.

[32] Akanbi, O.M., A.B. Odaibo and O.G. Ademowo, (2006). Effect of age and anti- MSP1 (19) antibody (IgG) level on prevalence of malaria in pregnancy in southwestern Nigeria. Sci. Res. Ann., 2: 33-38.

[33] Davis TM, Binh TQ, Thu le TA, Long TT, Johnston W, Robertson K, Barrett PH (2002): Glucose and lactate turnover in adults with falciparum malaria: effect of complications and antimalarial therapy.Trans R Soc Trop Med Hyg, 96:411-417.

[34] Woodrow, C.J., J.I. Penny and S. Krishna, 1999. Intraerythrocytic Plasmodium falciparum expresses a high affinity facilitative hexose transporter. J. Biol. Chem., 274: 7272- 7277.

[35] Davis TM, Looareesuwan S, Pukrittayakamee S, Levy JC, Nagachinta B, White NJ. (1993) Glucose turnover in severe falciparum malaria. Metabolism; 42:334-340.

[36] Dekker E, Romijn JA, Ekberg K, Wahren J, Van Thien H, Ackermans MT, et al., (1997) Glucose production and gluconeogenesis in adults with uncomplicated falciparum malaria. Am J Physiol; 272: E1059-1064.

[37] Tayek JA, Katz J (1997). Glucose production, recycling, Cori cycle, and gluconeogenesis In humans: relationship to serum cortisol. Am J Physiol; 272: E476-484.

[38] Arjen, D., F. Nosten, K. Stepniewska, N. Day and N. White, (2005). Artesunate versus quinine for treatment of severe falciparum malaria: A randomized trial. Lancet, 366: 717-725.

[39] Kayode OT, Kayode AA, Awonuga OO (2011). Status of selected hematological and biochemical parameters in malaria and malariatyphoid co-infection. J. Biol. Sci. 11:367-373.

[40] Onyesom I, Agho JE (2011). Changes in serum glucose and triacylglycerol levels induced by the co-administration of two different types of antimalarial drugs among some malarial patients in Edo-Delta Region of Nigeria. Asian J. Sci. Res. 4:78-83.

[41] Mizushima Y, Kato H, Ohmae H, Tanaka T, Bobogare A, Ishii A (1994). Prevalence of malaria and its relationship to anaemia, 
blood glucose levels and serum somatomedin C (IGF-1) levels in the Solomon Islands. Acta Tropica. 58(3-4): 207-210.

[42] Binh TQ, Davis TM, Johnston W, Thu LT, Boston R, Danh PT, Anh TK (1997). Glucose metabolism in severe malaria: minimal model analysis of the intravenous glucose tolerance test incorporating a stable glucose label. Metab. 46(12):1435-1440.

[43] Mohanty S, Mishra SK, Das BS, Satpathy SK, Mohanty D, Patnaik JK, Bose TK (1992): Altered plasma lipid pattern in falciparum malaria. Ann Trop Med Parasitol, 86:601-606.

[44] Das BS, Thurnham DI, Das DB (1996): Plasma $\alpha$-tocopherol, retinol, and carotenoids in children with falciparum malaria. Am J Clin Nutr, 64: 194-100.

[45] Kittl EM, Diridl G, Lenhart V, Neuwald C, Tomasits J, Pichler H, Bauer k (1992): HDL-cholesterol as a sensitive diagnostic criterion in malaria. Wien Klin Wochenschr, 104:21-24.

[46] Grellier P, Rigomier D, Clavey V, Fruchart JC, Schrevel J (1991): Lipid traffic between High density lipoproteins and Plasmodium falciparum -infected red blood cells. J Cell Biol, 112:267-277.

[47] Imrie H, Ferguson DJP, Carter M, Drain J, Schiflett A, Hajdur SL, Day KP (2004): Light and electron microscopical observations of the effects of high-density lipoprotein on growth of Plasmodium falciparum in vitro. Parasitol, 128:577-584.

[48] Maegraith B (1981). Aspects of the pathogenesis of malaria, Serum status of biochemical parameters in malaria. Southwest Asian J Trop Med. Pub. Health; 12: 251-267.

[49] Ibrahim HG, Ubom G (2005). Serum alkaline phosphatase activity as a potential biomarker for the integrity of the hepatic drainage system in acute falciparum malaria infection. The Internet journal of infectious Diseases; 4: 1-5.

[50] Sein KK, Aikawa M (1998). The prime role of plasma membrane cholesterol in the pathogenesis of immune evasion and clinical manifestations of falciparum malaria. Med Hypotheses, 51: 105110.

[51] Beckwith. R, Schenkel R. H. and Silverman P. H (1975). Qualitative analysis of phospholipids isolated from nonviable Plasmodium antigen, Experimental Parasitology, vol. 37, no. 2, pp. 164-172.

[52] Beach D.H, Sherman I. W, and Holz G. G (1977). Lipids of Plasmodium lophurae, and of erythrocytes and plasmas of normal and P. lophurae infected Pekin ducklings, Journal of Parasitology, vol. 63, no. 1, pp. 62-75. 